\title{
Hypo- and hypermelanotic cutaneous macules-retarded growth-intellectual disability syndrome
}

INSERM

\section{Source}

INSERM. (1999). Orphanet: an online rare disease and orphan drug data base. Hypo-and hypermelanotic cutaneous macules-retarded growth-intellectual disability syndrome. ORPHA:2435

Hypo- and hypermelanotic cutaneous macules-retarded growth-intellectual disability syndrome is a rare, genetic pigmentation anomaly of the skin disorder characterized by congenital hypomelanotic and hypermelanotic cutaneous macules associated with, in some patients, retarded growth and intellectual disability. There have been no further descriptions in the literature since 1978. 